Keynote Address

Canadian Association for the Study of Discourse and Writing

Wilfrid Laurier University, Waterloo, Canada

May 2012

\title{
The Historical Formation of Academic Identities: Rhetoric and Composition, Discourse and Writing
}

Lovise Wetherbee Phelps

\section{Introduction}

This talk originated in my work as a consultant at the University of Winnipeg, where I spent six weeks on a Fulbright Specialist grant in Spring 2011. I was invited to advise the Department of Writing, Rhetoric, and Communications on its plans for "program architecture renewal," which included critically assessing its programs, articulating levels of the curriculum, and charting future directions for the department. The grant had larger goals as well, charging me to study the development of writing and rhetorical studies in Canada as an emerging field seeking both definition and visibility. The Winnipeg faculty hoped that the project could highlight the importance of these studies, in relation to a vibrant discipline of rhetoric and composition in the U.S. and the global growth of interdisciplinary writing studies, and contribute to their prospects for cohesion and recognition in Canada. ${ }^{1}$ In this presentation, I hope to advance some of these broader goals, informed by my dual perspective as a longtime scholar in and of American rhetoric and composition and as a new student of Canadian work in discourse and writing. ${ }^{2}$ 
Reading the Canadian debates about discipline formation has prompted me to revisit and radically rethink enduring themes in my own scholarship: concepts of disciplinarity, interdisciplinarity, and their relations to academic identities, both collective and individual. I will develop and draw on some of these reconceptualizations today to analyze the Canadian situation and its prospects. I have also been fascinated by the Canadian emphasis on place, which I first identified as a curricular and institutional theme at Winnipeg and then found specified in the 2009 CASDW call for papers as three concepts-"terroir, territoire, nation." In part this talk may be thought of as a response to that call, an effort to think through the meaning of place for Canadian writing studies.

\section{An Emergent Identity?}

To bring the two dimensions of the Fulbright project together, part of my task was to characterize the unique identity of the Winnipeg department-the first department of writing and rhetoric in Canada-by "placing" it in contexts at different scales of description, from its local setting - the geography and demography of university, city, and province-to the broader landscape of North American writing instruction and rhetorical studies (Phelps, 2011). To understand the Canadian scene specifically, I read publications and reports about the history and current state of writing instruction in Canada as well as examples of Canadian scholarship in rhetoric and writing, and interviewed some prominent Canadian scholars at other institutions. 3 In these materials and conversations, many Canadian scholars expressed an aspiration to gain recognition for writing studies as an intellectual enterprise comparable to other disciplines in the Canadian system of higher education (Smith, 2006; Graves \& Graves, 2006; Whalen, 2011; Clary-Lemon, 2009; Landry, 2010). Frequently, these calls for "professionalization," "unification," and "centrality" are informed by historical comparisons with the formation of rhetoric and composition in the United States. It's a trope that I will use myself to organize these reflections-but I will want to complicate and ultimately challenge the standard version of that comparison.

I observed many signs that discourse and writing studies in Canada are coalescing to form an inclusive academic identity that may be "coming of age," in Tracy Whalen's (2011) term. One significant milestone is the decision to adopt a broader term-the Canadian Association for Studies of Discourse and Writing-for this organization, which Jennifer Clary-Lemon (2009) calls "the first real bid for a centralized locale for Canadian scholars of writing and rhetoric" (p. 97). But this identity is still indeterminate and, for most of the Canadian higher education system, remains under the radar, if not below notice. I chose the term "academic identity" over "discipline" in my title with some deliberation. For one thing, I wanted to avoid immediately engaging arguments about disciplinarity and the problem of naming whatever community is emerging in Canada. As 
placeholders, I've used terms that have some historical claim to visibility in identifying the field in each country: "rhetoric and composition" in the U.S., where it first gained purchase as the name for a doctoral consortium; and "discourse and writing," the terms CASDW chose to expand its "intellectual territory" ("The Territoire/Places," 2009). I will use "writing studies" more neutrally, as shorthand to indicate a common object of research and teaching, from whatever intellectual perspective. CASDW describes this object-writingas encompassing "both written and oral communication, including visual and digitally mediated communication" ("About CASDW," n.d.). 4 This tactic will allow me later to reintroduce the concept of disciplinarity, and the questions surrounding it, in a fresh way, as related to but distinct from the accomplishment of an academic identity for writing studies in Canada. For now, let me emphasize that part of what I mean by calling such an identity "academic" is that it is recognized and legitimated by the collective institutions of higher learning that form what we call "the academy" in a given nation-state.

Let me recap briefly what most of you know first-hand: the obstacles that work against the historical formation of such an academic identity for writing studies in Canada.

There's a well-documented history of the values that shaped Anglo-Canadian views of writing and writing instruction, framed in terms of opposition between the British cultural heritage and an American model disdained as "practical" (Brooks, 2002; Hubert \& Garrett-Petts, 2006). Canadian researchers have described the lingering psychological impact of these attitudes and their consequences as they played out in the Canadian system. For example, Russ Hunt (2006), after explaining the vacuum of attention to writing caused by the rejection of American composition, comments that "in this ... as in many other cultural matters, Canada finds itself defined (in its own terms) as primarily like, or not like, the U.S.” (p. 374). Similarly, Tania Smith (2006) suggests the enduring ambivalence of Canadians looking "south of the border to find precedents and patterns for the growth of their field," yet resisting imitation of American models, based on negative stereotypes of "composition" courses (p. 322). These tensions are amplified by the necessity for many Canadians to get their doctorates in American universities and publish their research in American journals.

This history has left a material legacy as well. Canadian scholars point to the sheer practical difficulty of assembling a single connected intellectual community with such a small base of people, spread out widely across a large, lightly populated country, with few opportunities through organizations and funded travel to meet, interact, and work with one another. Many scholars note that, in the absence of a requirement like the almost universal American first-year composition course, Canadians lack a broad, stable instructional platform that would provide a critical mass of practitioners with a common curricular mission and location from which to launch a disciplinary enterprise. Writing instruction historically followed WAC and WID models for the most part, springing up in ad hoc structures, contingently funded and located in departments and faculties of other 
disciplines (that is, disciplines not defined by writing or rhetoric as a primary object of study and subject of instruction) (Graves, 1994; Graves \& Graves, 2006). It is difficult to compose a nationally viable identity around practices of instruction that are so decentered and disparate, lacking common pedagogical philosophies, habits, formats, or students. What they have had most in common is the uniquely local nature of each case.

These observations don't mean that the only way to develop an academic identity is from an instructional base. Most accounts of the development of writing studies in Canada and elsewhere portray it as a teaching practice looking for a discipline-an intellectual content to rationalize and ground instruction. Though this might be historically accurate, the problem with conceiving it that way is that it takes both the practice itself (first-year composition in the U.S., WAC and WID models in Canada) and its institutional locations as a given, a point of departure from which it can be very difficult to depart, both literally and imaginatively. In a talk given at the University of Winnipeg, I suggested that, to think around these constraints, you could reverse the arrow of development and conceptualize Canadian writing studies as an intellectual movement looking for a place, not only literally (where it will physically and administratively "sit" in the university) but in the sense of the apparatus by which the academy defines and perpetuates such movements as disciplines (Phelps, "Writing Studies"). This shakes up any assumption that we know in advance the relationship between forming a discipline around the study of writing and practicing a postsecondary pedagogy of writing. And it would lead us to look for signs of that movement in the form of communities of inquiry where a critical mass of scholars gather and interact. Although hypothetically these could reside outside the university, in think tanks or research centers, for writing studies to have an intellectual identity that is specifically academic, they must find a place inside a nation's system of higher education.

In searching websites for evidence of such communities at Canadian universities, admittedly at a distance, I couldn't find any predictable relationship between the centers where writing instruction has developed most richly within universities and the distribution of scholars in rhetoric, writing, and discourse. In fact, as far as I've been able to discern, both the scientists and the humanists of the field are widely and thinly scattered, with occasional "pockets" where scholars, typically with mixed and variable disciplinary training and affiliations, come together, often embedded in programs with another focus. I got some sense that these configurations themselves shift rapidly, reconfiguring as scholars move, local personnel and positions of power turn over, and climates change for this kind of intellectual work or for the programs that host it. Only a few may be truly integrated, forming a coherent research enterprise capable of sustaining and reproducing itself, and not overly dependent on one or two charismatic figures. In part, this lack of coherence reflects the absence of doctoral programs and, more broadly, the vertical curricula of majors and graduate programs that are both signs of an established academic identity and also necessary to assemble the faculties that can create one. 
Despite the handicaps these conditions impose, nodes of scholarly work have developed and flourished. But they seem as disjointed and isolated from one another as the writing programs, hard to see as a single connected community. This fact is a major source of the indeterminacy I ascribed to the emergent identity of Canadian writing studies. It is not easily resolved because of the diversity of Canadian work that can, arguably, "count" as writing studies. In trying to answer this question for her pioneering survey of Canadian writing research, Jennifer Clary-Lemon (2009) includes "a host of things that ... may be grouped together by slim necessity" (p. 98), which are differentiated variously by method (discourse analysis), theory (genre studies), practical activity (pedagogy), or specialized discourse (technical communication). Her list is easily expanded by simply consulting the self-descriptions of Canadian scholars and programs or looking at the work presented at Canadian conferences on discourse, writing, and rhetoric. Russ Hunt (2006), describing Inkshed, and Tania Smith (2010), describing CSSR, each emphasize the multidisciplinarity and remarkable range of their constituencies in backgrounds, interests, and viewpoints.

The most distinctive of these scholarly nodes in Canada-for example, professional and technical communication, genre studies, media studies, rhetoric, or applied linguistics and discourse studies-appear to spring from different and often hybrid sources and traditions, distinguished by disciplinary training, focus or topoi of research, methods, and gestalt of a discipline. It would not be surprising to find these scholarly groups resistant to, or at least ambivalent about, the homogenization of these differences into a single discipline. And what would you call it? How would you categorize it-under science, humanities, education, communication? Liberal arts or professional? This is not an abstract issue, as you will find if you try to get representation for the field in taxonomies like the one SSHRC uses to categorize disciplines for funding applications. 5 This question still plagues American efforts (in what we call the "Visibility Project") to symbolize an identity that can appear unified to outsiders and simultaneously accommodate the emotional investments scholars make in their own sense of disciplinarity or interdisciplinarity. ${ }^{6}$

A lot of these issues manifest themselves in the unstable and contentious language of names and titles. At Winnipeg, I studied the terms applied to courses, tracks, faculty, programs, and the department itself, which failed to capture the laminated and complex intellectual backgrounds, traditions, identifications, and affiliations represented in the lived experience of the faculty. I found rampant polysemy, ambiguity, slippage, and confusion about the meanings and application of terms, and traced the same chaotic pattern in both Canadian and American titles for programs and departments. Winnipeg is lucky to have assembled in one place a faculty whose hybrid backgrounds and mélange of interests, projected into a vertical curriculum, model the potential for synergy among contributors to Canadian writing studies. But insofar as these terms index real, sharp 
differences among the diverse Canadian scholars interested in discourse and writing, Winnipeg was also a handy mini-model for the problems that confront any effort to consolidate writing studies in Canada as a common enterprise.

If writing studies is organized by an indefinite array of interpretations of its object and perspectives on it, then, as some Canadian scholars have asked, the question is whether this object is best studied, and the enterprise conceived collectively, in terms we can call disciplinary. Should it instead be envisioned as trans-, post-, or inter-disciplinary (Graves \& Graves, 2006; Smith, 2006)? Relatedly, does that mean it should be thought of as national (Canadian, American), postnational, international, or perhaps North American (Brooks, 2002)? How does Canadian bilingualism and the sense of linguistic-based "nations"-Anglo, French, and Native peoples-fit into the picture?7 Might we answer these questions differently for different topics or problems in writing studies-for example, for genre studies, or for the teaching of grammar? What's the most practical way to think about this, both in terms of function in the academy, like instructional responsibilities, hiring, or tenure and promotion, and in terms of how people understand their own identity as members of groups and communities of practice, emotionally and intellectually? In the next section, I will try to lay the ground for considering these questions.

I'll begin by drafting a distinction between "discipline" and "academic identity," and then propose how we might think about their relationship. ${ }^{8}$

A discipline, as I will define it, is a distributed network of people engaged in what some Canadians call "knowledge work" (Starke-Meyerring \& Paré, 2011), more or less loosely linked by some common object of attention. ${ }^{9}$ I want to borrow Latour's (2010) term here and say that such connected communities constantly work to compose a "common world." I like the connotations of this term because, as he describes the process, "this common world has to be built from utterly heterogeneous parts that will never make a whole, but at best a fragile, revisable, and diverse composite material" (p. 474). One can say that the discipline itself is reflexively constructed as a common world, in the same compositional and mosaic sense.

The basic function of disciplines as social groups is to provide through their interactions the cultural capital, symbolic resources, and emotional energies that enable people to accomplish this ongoing compositional activity. This description is adapted from Collins's (1998) monumental sociology of philosophical thinking across the globe and over the ages. Peer and intergenerational groups "make up a structured field of forces" (p. 7) for organizing and energizing a community's practice of intellectual work. Collins emphasizes direct, face-to-face interactions within groups as a primary means for "charging" participants with emotional energy, so that concentrations of scholars in close contact are crucial to the group's creativity. Intellectual communities can make connections and assemble themselves into networks at many different scales. But as he describes it, growth 
and expansion doesn't change the central role of these concentrated groups, who "dominate attention at the interactive core" (p. 6).

Collins has described three requisites for this kind of collective intellectual life in any culture: (1) "the intellectual network and its dynamics"; (2) the organizational base that supplies the resources for them to survive; and (3) "the political and economic forces which feed these organizations" (p. 51). In the West such intellectual activity was institutionalized in the academy, or institutions of higher learning, through the invention of the modern research university, which centralized and gave these networks autonomy and a sustainable base (Collins, 1998). ${ }^{10}$ That is where such activity was first cut up somewhat arbitrarily into disciplines (Anderson, 1993). Broadly, then, in our world the academy is the territoire for disciplinary networks, providing them with a place of their own. While "the academy" is now globalized, it still matters for intellectual networks, if they are to operate practically as communities, that they have a primary base and identity in their own country's educational system, its national academy.

Clearly, then, to function as a discipline in a particular national academy it is not sufficient, though it is necessary, for an emergent field to assemble itself as a productive network of intellectual activity. It is necessary for it to be identified as such, in the terms by which an academy recognizes disciplinarity, which we might summarize as having sufficient symbolic capital to be integrated into the system of disciplines. ${ }^{11}$ It must also find a place of its own in the sense of an organizational base for its activity, encompassing institutional and physical locations, organizing structures, and material resources to support its activity, all distributed across institutions. These two things together define what it means to achieve an academic identity: it is the ascribing of disciplinarity to a group and its work, coupled with the symbolic and material resources that ascription entails. An academic identity is an intellectual network in its public persona, as it is projected, legitimated, and treated by others as disciplinary. The others who count here are those who represent the power structures of the academy and its extensions into other institutions, including faculty, administration, unions, governmental bodies or agencies, databases, foundations, and other public and private organizations that make or influence educational policies and provide funding according to disciplinary categories. ${ }^{12}$

As I will try to explain, there is a difference between the lived reality and complexity of disciplinary networks and the more simplified identity that is ascribed, which has the nature of a rhetorical construct. It is actually co-constructed dynamically between the field and its audiences in specific events, but achieves stability over time in much the same way that genres do, through recurrence and its relationship to activity. There is also a complex interdependence between that construct on the one hand and the acquisition of resources on the other. One doesn't precede the other; rather, they feed each other.

Briefly, here are some important distinctions and differences between a discipline and its academic identity. A discipline is an ad hoc, opportunistic accomplishment, an 
assemblage rather than an intentional construction, no matter how many scholars try to define and determine it. Disciplines are open networks, self-organizing and constantly on the edge of chaos. Intellectual communities, because of the way they work through competition and argumentation, tend to be internally diverse and fractured and to move through cycles of division and merger. Networks are constantly in the process of being assembled, disassembled, and reassembled at different scales, for different purposes, and on different principles of commonality. Whether a network is called a "discipline," "subdiscipline," "interdiscipline," "field," or some other label is somewhat arbitrary, inconsistent in different contexts, and rhetorically motivated. There is no stable meaning for the kinds of differences these terms refer to in a given context, which might have to do with scale, specialization, how tightly linked the network is, what its sources are, or what holds it together. A clear distinction between a discipline and an interdisciplinary formation is hard to maintain. Most disciplines formed today, like rhetoric and composition, are born interdisciplinary in their sources, influences, and training of members, while multidisciplinary projects, interactions, and even integrations among widely disparate intellectual groups are frequent. Further, disciplines and their definitions change so rapidly, through specialization and recombination, that national organizations can't keep track of them-in a ten-year period, few are recognizable by title, description, or institutional location.

In contrast, academic identity as a particular image or ethos of a discipline can be at least partly designed. It can be strategically constructed for particular audiences whose perceptions and decisions can ascribe disciplinarity to a community or provide resources to secure its base. The symbolic construction of a discipline for outsiders deliberately simplifies and unifies complex and often contentious activities (and different gestalts of the discipline). As Anthony Cohen (1985) points out, this rhetorical expression of a community must "simplify its message down to a form and generality with which each of the members can identify their personal interests" (p. 35). Such general statements "are often sufficient distortions of individuals' aspirations that they would not pass within the community. However, the formation of such general positions for communication to another party often also feeds back into the community to inform its sense of self, and thereby embellish its symbolic boundaries" (p. 35).

Academic identity has a useful ambiguity in that it can also refer to an individual's own personal identity as an academic. Although I can't say much about it here, it is important to understand the complex ways that individuals, in becoming enculturated into a discipline, form their own professional identities through their participation not only in intellectual communities of practice-often more than one-but also in multiple other activity systems. I am particularly interested in the emotional investments people make when they identify with intellectual networks as disciplinary and draw emotional energy for creative work from their interactions. 
Such identifications intersect with, or in Prior's (1998) word are "laminated" with, other aspects of identity and identity formation, like nation, language, class, union membership, gender, immigrant status, and so on. Lamination is a feature, he argues, of all human interaction and activity. Disciplinary acculturation as part of identity formation is an important area of inquiry to understand disciplinarity and disciplines themselves, because it is how intellectual networks themselves are formed and remade. As Prior puts it, disciplinarity is "one domain of the general process by which people jointly constitute social worlds and identity in activity" (p. 26). ${ }^{13}$ Acculturation of individuals is also relevant to the practical work of constructing a collective academic identity because of the emotional connotations people attach to different concepts and experiences of disciplinarity, and to symbols of it, in part through the relations they create between their intellectual work as academics and other dimensions of their lives and histories. These often lead to claims and counterclaims about what counts as a discipline, and resistance to strategic compromises in constructing disciplinarity that seem to subsume or misrepresent individuals' primary communities of identification and practice.

In the course of working on visibility for U.S. rhetoric and composition, I observed tensions between centripetal forces supporting the drive for discipline formation and recognition, and centrifugal forces, in which people pushed against efforts to unify and bound the community-arguing post-disciplinary and anti-disciplinary positions, or seeking to differentiate and legitimate an array of specialized communities that I've called "micro-disciplines." My sense is that calls for division are loudest when people feel most secure, implicitly relying on the signs, symbols, and resources of disciplinarity, like tenured positions, that already give them a base. When this security appears more fragile, as happens in cycles, people are driven to band together to consolidate a stronger collective identity. Borrowing Casanave's terms, they make efforts toward coherence for the disciplinary self, involving a process of reconciliation "'needed to connect people's several identities from the different communities of practice they participate in"' (Wenger, 1998, qtd. in Casanave, 2002, p. 265).

The process by which an intellectual network assembles itself as a discipline and translates this complex activity into an academic identity is usefully called professionalization. There are complex overlaps and interdependencies in professionalization between processes and effects that build the capabilities and connectivity of intellectual networks; the material manifestations and resources they acquire or produce in and for this work; and the tools of persuasion that give the community visibility and salience to others. Many things actually serve these purposes simultaneously: they enable intellectual work, they establish it organizationally and materially, and they symbolize its presence and acceptance. You will recognize many of the features of disciplinarity that have this multifunctionality. For example, one academic standard for knowledge work is that it be made public and therefore open to criticism. This 
translates, in professionalization, to publication channels like journals, presses, and reviewing procedures for people, publications, and programs, which collectively create a public presence and are cited as signs of disciplinarity. The same means serve a more fundamental aim of establishing connectivity and fostering interactions within the community, which is the heart of its disciplinarity. Other such features are professional organizations; conferences and symposia; a body of published texts; citations; websites and listservs; faculty positions, including faculty administrators; tenure-track lines; guest speakerships; instructional programs; and institutional structures like centers and departments.

Based on my experience in the Visibility Project, where we successfully argued the case for rhetoric and composition to several different government agencies and managers of informational databases, let me list what I've found to be the most fundamental features of disciplinarity, both intrinsically and to observers, and which translate through the process of professionalization to the most compelling symbols and arguments for an academic identity.

These are:

- a connected intellectual community sustained over time and space

- a critical mass of people in that network, their distribution across multiple institutions, and their concentration in more than a few of these

- the ability to reproduce itself

- an educational mission or social responsibility related to its knowledge work.

Let me comment briefly on these.

An intellectual network sustains itself by activity, growth, and connectivity, acquiring, deploying, and generating resources through professionalization. These then become symbols and tools of persuasion in rhetorically constructing identity. A critical mass is defined contextually, but since the networks of writing studies are small relative to the sciences (which dwarf the humanities and social sciences combined), in delineating the field as disciplinary they must move up the scale of abstraction from specialized groups to a broader coalition. The ability to reproduce itself is the most critical of all these features. Doctoral programs sustain the community genealogically and as a network of ideas, and therefore stabilize its identity. That makes them crucial. Literally, for U.S. rhetoric and composition, in one context, recognition of disciplinarity rested solely on demonstrating a specific number of doctoral programs, distributed over a minimum number of universities, each producing graduates at a certain rate, sustained over at least five years. In another context, however, the criterion was the density and distribution of instructional programs offering degrees at various levels, but especially undergraduate majors (for details, see Phelps \& Ackerman, 2010, on the Visibility Project.) The importance of majors (and MA degrees) is that, unlike doctoral programs, they require substantial numbers of disciplinary faculty, which widens the material base for writing studies. 
Most of these features and criteria are intrinsically tied to place: the notions of a material and organizational base; organizing structures and institutional locations on campuses, like departments or labs, in buildings where people can live and work as academics; both concentrations and distribution across geographical and institutional space. The spaces and sites of the academy, both literally and metaphorically, have a certain traditional structure that is supposed, at least, to correspond to the structures of disciplines. I question that claim, in general, as based on a myth of unified disciplinarity and a misconception of the contemporary nature and work of the academy. I have read proposals for redesigning the built environment and organizational structures of universities to better accommodate, for example, student learning communities, community engagement, casual interactions between different disciplinary groups, and multidisciplinary research on social problems. Some institutions, including Winnipeg, have even done some of that. But I think the field of writing studies is a special case in the way its institutional logic challenges the way academic institutions organize themselves as places and into territories, and I'd like to explore the point briefly because it highlights both the difficulties and the opportunities associated with the decenteredness of Canadian writing instruction and, to some extent, writing studies.

In previous work (Phelps, 1991; Phelps, 2002), I made the argument that the institutional logic of U.S. writing programs challenges the traditional structures of the American academy because "there is a fundamental mismatch between the needs, goals, and nontraditional functions of writing programs and the available forms and structures in higher education institutions for organizing and implementing them" (2002, p. 7). This mismatch is concealed when a writing program is embedded deep in an English department, but when the two are decoupled, it becomes evident that the functions of writing programs, even in a general education curriculum and more so in WAC/WID programs and writing centers, "are distributed and decentered [across the faculty and units of the university] in a way that parallels the diffusion of writing itself" (p. 7) and, therefore, its scholarship. There is, I claimed, an "isomorphism . . . between the intellectual structure of composition and rhetoric, as a highly intertextual, multisourced discipline, and the unconventional ways it ties its teaching project [and its research projects] to many different departments and colleges" (1991, p. 159). But at the same time intellectual networks in writing studies also have a need for more centered, place-based structurestheir own territory-where they can interact in a human-size community for living and learning, both with peers and with students in majors and graduate programs who may identify with the discipline. The problem then is to design writing units as structures and places for writing faculty to "reconcile needs, features, and functions that gravitate toward one of these two poles ... the decentered, loosely coupled network and the focused core; the generalist, distributed instructional mission and the expertise that grounds it and finds its source and expression in scholarship and advanced teaching” (2002, p. 11). 
I find this analysis very suggestive of the potential for Canadian writing studies to explore the idea that its decentered arrangements for writing instruction and even for research communities model an institutional logic that corresponds to and facilitates important intellectual features, functions, and needs of the discipline. I am thinking of amplifying the notion of place as territoire in and of the academy with the metaphor of terroir, which I understand to mean something like the way all the elements of a particular environment combine to make a product like wine unique to its place. I am thinking of writing studies as a grape, the way it grows in a particular place as a unique expression of the totality of how its local network interacts with and responds to that environment-its geography and demography, financial resources, the university's mission, ethos, and themes, institutional structures and sites for its work, other disciplines it works with, and so on. In retrospect, I realize that my contextual study of Winnipeg's Department of Writing, Rhetoric, and Communications-which I described as "fitting the university like a glove"-was precisely a study of its terroir. The same might be said of a number of other case studies of the highly localized nature of writing programs in Canada, but I have not seen similar studies of its research communities. I will return to these thoughts in discussing possible directions for systematically constructing an academic identity for writing studies in Canada.

First, I want to fulfill my promise to take up critically the comparison with the United States that has so shaped and colored your own historical experience and perceptions of writing studies in Canada. This historical work was obviously very valuable in tracing the source and long-term consequences of an opposition that defined Canadian writing instruction by its "difference" from the so-called "American model." But to the extent that the binary itself continues to constrain the Canadian imagination of what its own writing studies can be, or of the potentially pluralistic relations between the Canadian and American communities, it needs to be deconstructed and reconstructed.

My first problem with the comparison is that it rests on an image of American rhetoric and composition and its historical formation that is oversimplified, outdated, and radically incomplete (and I've revised these words to make them more polite). I don't blame the Canadians, who are reading our discipline at a distance, just as I am your own landscape, where misreadings and simplifications are inevitable. In any case, you are not responsible for writing our histories. I think the ones we have for U.S. writing studies are inadequate to account for the field's complexity, which requires a rich array of diverse accounts. Instead, too often our journals and graduate education uncritically perpetuate a self-representation of the field that treats a thin slice of history as the whole, even that viewed from a highly interested perspective (see Phelps, 1999). It's only now that counterhistories are beginning to appear that fill in missing pieces and refigure the development of the field in different images, each of them arguing for different futures.

Even focusing only on the first-year writing requirement, oversimplification 
distorts the comparison. For example, this course, originally "Freshman English," is taken by Canadians to illustrate American practicality. But in the American academy, attitudes toward the practical, and specifically toward this course, are extremely conflicted. In English departments they bear a lot of resemblance to those in Canada, albeit with different historical sources. Whereas Canadian English departments off-loaded writing instruction to other disciplines, through writing centers and ad hoc arrangements, American English departments off-loaded it to nontenure-track instructors and teaching assistants and, lately, to community colleges. Even within the field itself, ambivalence toward the practical is almost a signature feature, fracturing its theorists and practitioners, even more so as the field has succeeded in securing an academic identity (North, 1987; Phelps, 2008; Olson, 2002; Ede, 2004).

Complicating the view of American first-year writing doesn't overcome the reductionism that takes this part for the whole. It's necessary to look comprehensively at the whole picture of writing instruction in U.S. higher education, both historically and contemporaneously, to see where and how it is offered, or was at some time offered, other than in first-year composition. You can do it as a thought experiment: ask yourself, to what extent has the U.S. provided alternate models for Canadian writing instruction? First, you will notice professional and technical communication, writing across the disciplines, and (more recently) majors, certificates, and graduate programs. In some cases programs identified with writing studies include journalism or creative writing or specializations like forensic writing. ${ }^{14}$ In addition, newer histories now go outside the academy to document how writing or rhetoric has been taught or learned in sites-called the extracurriculumlike women's clubs, temperance societies, churches, the suffrage movement, prisons, unions, agricultural societies like the Grange, and so on. The range of the extracurriculum is widening all the time. Contemporaneously, instruction by writing and rhetoric faculty is moving outside the academy to promote learning by diverse groups in various places, from community literacy centers and schools to workplaces. Having done this experiment, Canadians will realize that there is not one but a plethora of American models for instruction, including some, like WAC and WID, writing centers, technical communication and majors, that have substantially influenced Canadian writing studies.

A deeper and ultimately more transformative critique is that both sides of the opposition begin with writing instruction as the source and motive of disciplinary development. Earlier, I suggested reversing this to historicize either field as an intellectual movement in search of an academic home, which entails for most if not all disciplines an instructional mission. If we apply this move to the first-year writing versus WAC/WID choices, we get a very interesting rereading of what it means in terms of the object of study of the discipline. If you consider the object of study generally to be writing as it is practiced, learned, and enculturated over the life span, then each country has selectively focused on a part of the arc of writing development. The U.S. starts earlier-focusing on entry to 
college (university, in Canadian terms) and, historically, also on secondary schools; Canada generally starts later, with entry of students into the disciplines, and follows them more systematically into the workplace and adult nonacademic practice. The notion and span of academic writing is therefore a bit different, with more Canadian emphasis on faculty academic writing as well as professional writing in context. Canadians have focused sharply on transitions, from university writing to work or from undergraduate writing to graduate study. But from a research perspective, why isn't the transition from school to university just as important and interesting for studying issues of writing and identity? Conversely, it appears that American research has focused heavily on the transition to college, and on writing development for undergraduates, without sufficient emphasis on ongoing learning and later transitions. This is especially problematic because of increasing numbers of students who don't fall in the traditional 18-22 age range, and who are often already working.

The whole life span of available writing and rhetorical practices and their learning, taken as the central focus of a discipline, implies a spectrum of available opportunities not only for research but also for instruction or intervention by the discipline. Selections in both the U.S. and Canada of a particular part of the spectrum for instructional responsibility are pragmatic and historically contingent and, from the perspective of research, often arbitrary. But since the two decisions are interdependent, in practice what is instructed often defines and constrains what is researched. As the discipline addresses a greater range in the object of study, a natural part of expansion, it must continue to make selections, mostly based on opportunities or practical constraints, about which parts and dimensions of its object of study will become subjects of academic instruction or more indirect intervention to improve cultural instruction generally. Conversely, when it does seize these opportunities-for example, service learning and community engagementnew research possibilities open up.

Starting with research instead of instruction, and then tracing their interdependence, allows one to reconstruct the opposition between Canadian and American disciplines of writing studies in terms of a more pluralistic set of relations: besides difference, exploring parallels, analogies, and interactions, and, in the case of differences (plural), examining more closely those where Canada has the advantage. To me it suggests an expanded field of research questions that might be asked about Canadian writing and rhetoric studies and instruction. For example, I know almost nothing about relations between Canadian writing studies and the secondary schools, except that Russ Hunt (2006) had an intriguing few paragraphs about the rise and fall of influences from British educators like James Britton on both American and Canadian intellectual networks. Potentially, Canada can extend the parameters of the discipline downward into the schools just as it has extended them upward into graduate school and outward into the workplace, and into the extracurriculum where people write and learn to write in a wide 
variety of settings.

The last point I want to make about the comparison is that it should be reconstructed to go both ways. When I was writing my dissertation, I attended the 1979 Ottawa conference at Carleton, which Jim Zebroski (2012) has recently called one of the most important founding events in U.S. rhetoric and composition. I have been reading Canadian scholars' work throughout my whole career and been deeply influenced by some of it, but I didn't explicitly read it as Canadian. Scholars often don't identify themselves as such, and they write theories-for example, of "workplace writing" or "genre"-as if they are universals. Even when I knew they were Canadian, I read many of these scholars unconsciously as "one of us." It's like the way I thought about my own identity. My full name is Louise LaRochelle Wetherbee Phelps, and I have always described myself as English, Irish, Scots, and French. But my grandparents on one side were French-Canadian, from Quebec, and British-Canadian, from Ontario. I only realized when I was in Winnipeg that I could describe myself as half-Canadian. It seems to me that some of our revisionist histories, on one side or the other, should look into the role of Canadian scholars in shaping U.S. rhetoric and composition, perhaps working toward a more concrete notion of North American writing studies. In any case, Canadian discourse and writing scholars need to set aside this one-dimensional comparison now and make it pluralistic and productive. The Canadian discipline need not think of itself any more as defined either by imitation nor opposition to a shrunken version of American composition. It has many more options and influences than that.

\section{A Path Forward}

Much of what I have said in this piece has very concrete implications and potentials for a way forward in crafting an academic identity for Canadian writing studies. It appears to be, as many have suggested, already an emerging discipline, in the sense of having a fairly robust intellectual network that is growing and ramifying. Once set in motion, this is a selfperpetuating activity as long as it has minimal conditions for people to continue, although it must add people, especially a new generation, to sustain itself. It is, however, probably not as connected as it needs to be. Of the criteria I mentioned that simultaneously characterize a discipline and make it visible to others, the most important is the ability to reproduce itself, which means that developing more doctoral programs is a key priority.

For many years a small group of you has worked at professionalizing in a variety of

ways, including doing some of the naming and self-description that helps a group move toward a sense of identity as symbolically constructed. I would suggest that this is a point to enlist and expand the broader community to pursue this process more systematically, in the form of different kinds of work that are deliberate, coordinated, and quickly exploited, translated into symbolic capital and material resources, each feeding the other. 
For example, professionalization involves rhetorical work; organizational work; political work; work to set up connectivity and promote interactions; funding work; faculty development work; mentoring work; institutional work like reviewing, making tenure and promotion cases, hiring; and work like that of the Visibility Project that targets database codes and informational networks. Some of your own knowledge work can be directed at your own discipline, especially its research communities: historicizing it, theorizing it, doing case studies and comparisons.

In conclusion, let me say how thoroughly fascinated I am by the prospects of Canadian writing studies. I like Latour's distinction between prospect-'l'avenir"-and future-"le futur" (2010). In contrast to a utopian future that never comes, he likes to talk about many prospects-the unpredictable shape of things to come. Prospects mean "it is time to compose-in all the meanings of the word, including to compose with, that is to compromise, to care, to move slowly, with caution and precaution ... innovating as never before but with precaution!” (p. 487). The proper response is, in a Quaker saying I often quote, "Proceed as way opens." I hope to continue, in collaboration with Canadian and American colleagues, to research the historical formation of Canadian disciplinarity and academic identity, and I would love to become a partner and help where I can!

\section{Postscript: A Scenario for Action}

The lively discussion following this talk at CASDW 2012 led me to speculate on what kinds of practical action might constitute the "work" that I proposed should be undertaken to achieve academic identity for writing studies in Canada. Here's a scenario I have imagined for taking some concrete, achievable steps toward that goal. I hope it will be usefully suggestive.

A workable design for this project must set priorities and take into account current constraints. Here are the priorities I assume:

- to make progress toward creating a collective self-understanding and sense of community, as comprehensive as possible in its membership

- to target influential individuals and groups and begin the process of articulating an academic identity that they will accept and incorporate into decision making (e.g., in coding academic fields and programs or awarding grants)

- to achieve reproducibility (in advance of having a critical mass of graduate programs)

\section{Strategies}

1. Form an "alliance of societies" in writing, discourse, and rhetoric studies, for purposes 
of consolidating identity and gaining visibility for the allied groups as a whole, with the following initial functions:

- Create a committee or board, consisting of representatives from each society, that meets once a year at one of the conferences of the societies (rotating these) and sets an agenda for the collective activity of the alliance

- Broadly, set goals for the alliance and enable the constituent societies to support one another and communicate with one another to gain visibility for all

- Persuade the constituent societies to participate in an "embedding" program, in which these representatives, or others whom their societies choose, attend yearly a meeting of a society other than the one they represent, rotating through the various constituent societies. They would act as observers and notetakers, reporting back to their own societies in order to build understanding of the culture and organization of each group, and, not incidentally, getting to know each other face to face

- Set and address other specific goals (see \#2-4).

2. Set up a task force to identify database codes and target opportunities to change them to include writing, discourse, and rhetoric as a whole and/or as a set of specific "fields," depending on the particular code and its functions and structure.

3. Establish an ability to reproduce the "field" (i.e., the set of participating disciplines and specializations) as a community of scholars even before achieving a critical mass of graduate programs. Suggestions:

- Recruit Canadians to get degrees and identify with these disciplines and the whole field at levels before doctoral education: undergraduate majors, MA students in cognate fields, faculty who teach writing/discourse/rhetoric but lack doctoral degrees

- Encourage and support Canadians to gain doctorates, whether in Canada, the U.S., or elsewhere, that reflect the specializations of these societies or can be adapted to do so

- Systematically help them-using social media, conference attendance, distance technologies, cross-institutional collaboration on conference presentations, and other means-to form peer generational networks as soon as they begin their graduate programs, no matter where they are geographically

- Explicitly encourage graduate students to identify with their own cohort and to network, not only with their Canadian peers, but also with U.S. and international scholars, as early as possible

- Work with graduate directors and faculty across institutions and national borders to assist students to find and adapt programs to their needs and to make these contacts

- Encourage doctoral students to request outside scholars as mentors and 
readers on their dissertation committees. U.S. programs allow and encourage outside mentors/readers on dissertation committees; Canadian senior scholars and even retired Canadian faculty could organize themselves to serve in this role, both in Canadian and in U.S. programs.

4. In order for jobs to be available in Canada for these graduates, focus on the difficult issues of upgrading positions (to research stream) where suitable and working on the labour issues related to the teaching stream.

What makes this work possible (but challenging) is getting a core group to make a sustained commitment to it: leaders who work to set up and sustain an infrastructure of communication and act decisively on a few priorities. These leaders in turn need the support of their constituencies to carry out the agenda the groups agree on together. Such work, frankly, takes years to come to fruition, and requires a great deal of persistence and determination. Think inclusively!

\section{Notes}

1. My broader charge was to understand the Canadian experience and history of writing studies by comparison with the development of rhetoric and composition in the U.S., drawing in part on my experience as leader of a project to gain recognition for rhetoric and composition as a discipline (see note 6, on the Visibility Project).

2. I'm indebted to all my Winnipeg colleagues, whose writings and conversations instructed me not only about their own department and scholarship but also about the broader Canadian landscape of instruction and research.

3. Those interviewed included Doug Brent, Roger Graves, Margaret Proctor, and Catherine Schryer. I thank them for their illuminating conversations and correspondence.

4. In its 2009 program, CASDW goes on to designate particular places and purposes that are of primary concern to scholars and teachers in this organization: writing as practiced in "academic and nonacademic settings-higher education, business, government, and nonprofit organizations"; for "democratic participation in society as well as ... knowledge work in workplace, research, government, and public settings." These specifications are distinctively Canadian. The actual and potential sites or "places" for both research and teaching are much broader in the U.S., including (for instance) retirement homes, schools (elementary and secondary), and the "extracurriculum"-places like labour unions and community literacy sites. At its broadest scope, U.S. rhetoric and composition/writing studies as a field of research and teaching encompasses the practice and continued learning of writing over the life span, in any setting. 
5. I noted, of course, that SSHRC categories do not include writing/discourse/rhetoric studies. After I left Winnipeg, my colleagues looked into the possibility, through their SSHRC representative Catherine Taylor, of obtaining a separate category for the field, but nothing came of it. It seems futile to pursue this goal through purely local efforts, especially in current economic circumstances. In my experience, it would take a broadbased, aggressive disciplinary effort even to get a hearing for the request, and probably a lot more time and work to succeed.

6. The Visibility Project, which began in the Consortium of Doctoral Programs in Rhetoric and Composition and then migrated to a committee of the Conference on College Composition and Communication, is a sustained and successful effort to gain recognition for the field through the channel of databases and their codes for disciplines and educational programs. It was, and continues to be, extremely difficult to get any agreement to represent our many specializations as a unified field, under any available term for the whole. See Phelps and Ackerman (2010) for details of the process, which might be useful to Canadians in pursuing the same goals, despite the idiosyncrasies of the codes and bureaucracies involved.

7. I thank Céline Beaudet for explaining this Canadian concept of "nation" to me.

8. Although I can't cite here all the theories that influenced these distinctions, among the most important are the work of Randall Collins (1998) on the sociology of intellectual networks, Bruno Latour (2005) on the production of the social, Anthony Cohen (1985) on the symbolic construction of community, Ron Scollon and Suzanne Wong Scollon (2003) on geosemiotics, and Paul Prior (1998), Christine Casanave (2002), and James Zebroski (2012) on academic identities and disciplinarity. These ideas converge with concepts of disciplinarity, communities of practice, and identity formation developed in genre studies by Canadians and others (e.g., Starke-Meyerring et al., 2011; Bawarshi \& Reiff, 2010; Coe, Lingard, \& Teslenko, 2002; Artemeva \& Freedman, 2006).

9. Compare the conception of "intellectual work" in relation to different forms and uses of knowledge in "Making Faculty Work Visible" (MLA Commission on Service, 1996).

10. Collins (1998) describes three layers for the social production of ideas: an ideational layer (ideas and social networks); a material base; and "the surrounding politicaleconomic context which generated these organizational changes" (p. 622). He asserts that the ideas and development of intellectual communities can't be reduced to either the base or the forces, but external shocks, by reconfiguring these layers and their relationship, do energize intellectuals and bring about creative change. Although the university gave the intellectual life autonomy, turmoil in the world outside the academy works its way through these layers to affect the opportunities and conditions for particular intellectual networks to thrive.

11. Although the system of disciplines is in many respects cosmopolitan and international, I think one could make a case that, first, some disciplines are specific to place (as 
composition arose in the U.S. and was for a long time an American discipline) and, second, that many if not all have a specific character (and sometimes name) in a given national academy (or, perhaps, a transnational one, as in Europe) that is place-based. Languages, art, history, and rhetoric are obvious examples. This specific character applies to scholarship as well as to instruction. Thus I think it is perfectly meaningful to speak of Canadian writing studies (or rhetoric or media studies) considered autonomously as having its own unique character as a discipline, despite its participation in larger North American, Commonwealth, and international networks of writing studies.

12. Public perceptions and ascriptions are important too, though more indirect. For example, they affect how students learn about and new members are recruited into intellectual networks.

13. Thus a discipline itself, according to Prior (1998), can be described as laminated, a network that is "interactively stabilized . . . by the co-evolution of aligned people, institutions, artifacts and practices, and exists in reciprocal relations to other sociohistoric spheres of activity (workplaces, national government, the international system, the family, public media, religious organizations)" (p. 2).

14. Advanced writing instruction, specialized as journalism, creative writing, and technical writing, developed almost contemporaneously with first-year composition, as documented by Katherine Adams (1993). It began in the late $19^{\text {th }}$ century as part of the professionalization of work and the specialization of academic instruction.

\section{References}

About CASDW (n.d.). Canadian Association for the Study of Discourse and Writing. Retrieved from http://casdwacr.wordpress.com/about/.

Adams, K. H. (1993). A History of Professional Writing Instruction in American Colleges: Years of Acceptance, Growth, and Doubt. Dallas: Southern University Press.

Anderson, Charles W. (1993). Prescribing the Life of the Mind: An Essay on the Purpose of the University, the Aims of Liberal Education, the Competence of Citizens, and the Cultivation of Practical Reason. Madison: University of Wisconsin Press.

Artemeva, N., \& Freedman, A. (Eds.). (2006). Rhetorical Genre Studies and Beyond. Winnipeg: Inkshed.

Bawarshi, A. S., \& Reiff, M. J. (2010). Genre: An Introduction to History, Theory, Research, and Pedagogy. West Lafayette: Parlor Press.

Brooks, Kevin. (2002). National culture and the first-year English curriculum: A historical study of 'composition' in Canadian universities. American Review of Canadian Studies, 32(4), 673-94. Rpt. in Roger Graves \& Heather Graves (Eds.) (2006), Writing Centres, Writing Seminars, Writing Cultures: Writing Instruction in 
Anglo-Canadian Universities (pp. 95-119). Winnipeg: Inkshed.

Casanave, Christine Pearson. (2002). Writing Games: Multicultural Case Studies of Academic Literacy Practices in Higher Education. Mahwah: Erlbaum.

Clary-Lemon, Jennifer. (2009). Shifting traditions: Writing research in Canada. American Review of Canadian Studies, 39(2), 94-111.

Coe, R., Lingard, L., \& Teslenko, T. (Eds.). (2002). The Rhetoric and Ideology of Genre. Cresskill, NJ: Hampton Press.

Cohen, Anthony P. (1985). The Symbolic Construction of Community. London: Routledge. Collins, Randall. (1998). The Sociology of Philosophies: A Global Theory of Intellectual Change. Cambridge, MA: Harvard University Press.

Ede, L. (2004). Situating Composition: Composition Studies and the Politics of Location. Carbondale: Southern Illinois University Press.

Graves, Roger. (1994). Writing Instruction in Canadian Universities. Winnipeg: Inkshed. Graves, Roger, \& Graves, Heather. (2006). Introduction: Writing centres, writing seminars, writing culture. In Roger Graves \& Heather Graves (Eds.), Writing Centres, Writing Seminars, Writing Cultures: Writing Instruction in AngloCanadian Universities (pp. 1-21). Winnipeg: Inkshed.

Graves, Roger, \& Graves, Heather. (Eds.). (2006). Writing Centres, Writing Seminars, Writing Cultures: Writing Instruction in Anglo-Canadian Universities. Winnipeg: Inkshed.

Hubert, Henry, \& Garrett-Petts, Will. (2006). The rhetoric of 'intelligent recreation': An historical narrative of English Studies in Canada. In Roger Graves \& Heather Graves (Eds.), Writing Centres, Writing Seminars, Writing Cultures: Writing Instruction in Anglo-Canadian Universities (pp. 61-93). Winnipeg: Inkshed.

Hunt, Russell. (2006). Afterword: Writing under the curriculum. In Roger Graves \& Heather Graves (Eds.), Writing Centres, Writing Seminars, Writing Cultures: Writing Instruction in Anglo-Canadian Universities (pp. 371-383). Winnipeg: Inkshed.

Landry, Dana. (2010). Writing studies' room of its own. In Heather Graves \& Roger Graves (Eds.), Interdisciplinarity: Thinking and Writing Beyond Borders (pp. 31-41). Edmonton: Canadian Association for the Study of Discourse and Writing.

Latour, Bruno. (2010). An attempt at a 'compositionist manifesto'. New Literary History 41, 471-90.

Latour, Bruno. (2005). Reassembling the Social: An Introduction to Actor-NetworkTheory. New York: Oxford University Press.

MLA Commission on Professional Service. (1996). Making faculty work visible: Reinterpreting professional service, tenure, and research in the fields of language and literature. Profession 1996, 161-216.

North, Stephen M. (1987). The Making of Knowledge in Composition: Portrait of an Emerging Field. Upper Montclair: Boynton/Cook.

Olson, Gary A. (2002). Rhetoric and Composition as Intellectual Work. Carbondale: 
Southern Illinois University Press

Phelps, Louise Wetherbee. (1991). The institutional logic of writing programs: Catalyst, laboratory, and pattern for change. In Richard Bullock \& John Trimbur (Eds.), The Politics of Writing Instruction (pp. 155-170). Portsmouth, NH: Boynton/Cook Heinemann.

Phelps, Louise Wetherbee. (1999). Paths not taken: Recovering history as alternate future. In Mary Rosner, Beth Boehm, \& Debra Journet (Eds.), History, Reflection and Narrative: The Professionalization of Composition, 1963-1983 (pp. 39-58). Stamford, CT: Ablex.

Phelps, Louise Wetherbee. (2002, November). Matching form to function in writing program design. Invited talk at Michigan State University.

Phelps, Louise Wetherbee. (2008, April). The symbolic construction of disciplinarity: Composing the 'integrated' past, the fragmented present, and myths of future unity. Talk at the Conference on College Composition and Communication, New Orleans. Phelps, Louise Wetherbee. (2011). Liminal Practice in a Maturing Writing Department. Report to Department of Rhetoric, Writing, and Communications, University of Winnipeg. Retrieved from http://rhetoric.uwinnipeg.ca/Louise_Wetherbee_ Phelps /RWC_rpt_LWP_final_corrected.pdf.

Phelps, Louise Wetherbee. (2011, May). Writing Studies at the University of Winnipeg: A Strategic Opportunity. Distinguished Speaker Lecture. Appendix 1, Liminal Practice in a Maturing Writing Department, Report to Department of Rhetoric, Writing, and Communications, University of Winnipeg.

Phelps, Louise Wetherbee, \& Ackerman, John M. (2010). Making the case for disciplinarity in rhetoric, composition, and writing studies. CCC 62(1), 180-215.

Prior, Paul. (1998). Writing/Disciplinarity: A Sociohistoric Account of Literate Activity in the Academy. Mahwah, NJ: Erlbaum.

Scollon, Ron, \& Scollon, Suzie Wong. (2003). Discourses in Place: Language in the Material World. London: Routledge.

Smith, Tania S. (2006). Recent trends in undergraduate writing courses and programs in Canadian universities. In Roger Graves \& Heather Graves (Eds.), Writing Centres, Writing Seminars, Writing Cultures: Writing Instruction in Anglo-Canadian Universities (pp. 319-370). Winnipeg: Inkshed.

Smith, Tania S. (2010, June) Canadian society and the study of rhetoric. Edu*Rhetor. Retrieved from http://edurhetor.wordpress.com/2010/06/12/canadian-societyand-the-study-of-rhetoric/.

Starke-Meyerring, Doreen, et al. (Eds.). (2011). Writing in Knowledge Societies. Fort Collins, CO: WAC Clearinghouse.

Starke-Meyerring, Doreen, \& Paré, Anthony. (2011). The roles of writing in knowledge societies: Questions, exigencies, and implications for the study and teaching of Writing. In Doreen Starke-Meyerring et al. (Eds.), Writing in Knowledge Societies (pp. 3-28). Fort Collins, CO: WAC Clearinghouse. 
The territoire/places of writing studies in higher education: Canadian and international perspectives. (2009). Canadian Association for the Study of Discourse and Writing. Retrieved from http://www.cs.umanitoba.ca/ casdw/en/2009cfp.htm.

Wenger, Etienne. (1998). Communities of Practice: Learning, Meaning, and Identity. Cambridge, England: Cambridge University Press.

Whalen, Tracy. (2011). Introduction. Writing programs and coming of age: Thinking outside the scare quotes. Canadian Journal for Studies in Discourse and Writing, 23(1), 1-10.

Zebroski, James T. (2012). Hidden from history: English education and the multiple origins of composition studies, 1960-2000. In Patricia La mbert Stock ( E d . ), Composition's Roots in English Education (pp. 26-50). Portsmouth, NH: Boynton/Cook Heinemann.

\section{Notes on Contributor}

Louise Wetherbee Phelps is Emeritus Professor of Writing and Rhetoric at Syracuse University, where, as founding director of the Writing Program, she led its development into an independent department with a doctoral degree and undergraduate major. Currently Adjunct Professor of Rhetoric and Writing at Old Dominion University, she teaches in the English Department's interdisciplinary PhD program. Dr. Phelps is the author of Composition as a Human Science: Contributions to the Self-Understanding of a Discipline (1988), two co-edited volumes, and more than 45 essays on composition, rhetoric, doctoral education, and writing program administration. Recently, she coordinated a successful initiative to add the field of composition and rhetoric/writing studies to disciplinary classification systems used in American higher education databases. In 2011 she spent six weeks consulting at the University of Winnipeg as a Fulbright Specialist, and her current research includes a co-authored book on interdependencies between Canadian and U.S. writing studies. 